\title{
Analysing production and financial data from farmers can serve as a tool for identifying opportunities for enhancing extension delivery among the rural poultry sub-sector in Zambia
}

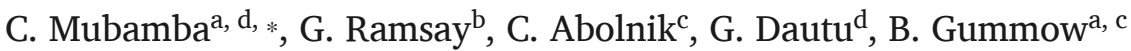 \\ a Discipline of Veterinary Sciences, College of Public Health Medical and Veterinary Sciences James Cook University, Queensland, 4811, QLD, Australia \\ ${ }^{b}$ School of Animal and Veterinary Sciences and Graham Centre for Agricultural Innovation, Charles Sturt University, Wagga Wagga, New South Wales, Australia ${ }^{c}$ Department of \\ Production Animal Studies, Faculty of Veterinary Science, University of Pretoria, Pretoria, South Africa

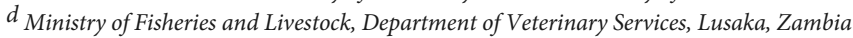

\begin{abstract}
A B S T R A C T
There are limited data on production and financial performance of the rural poultry sector in developing countries like Zambia that could be used by extension services as a feedback loop to enhance service delivery in the sector. Thus, a study that used production and financial data obtained from poultry farmers of Eastern Zambia was conducted to describe the rural poultry sub-sector and conduct financial analysis. It compared the financial performance of indigenous chicken production to broiler and layer production. The aim of the study was to identify opportunities and knowledge gaps among poultry farmers that could be used to initiate and enhance a participatory extension approach and build capacity of farmers in the sector. Descriptive, spatial, gross margin and breakeven analysis was used to analyse data obtained from 459 rural poultry farmers and expert opinion from 5 local extension workers.

Poultry ranked highest in terms of popularity and numbers when compared with other animals kept by respondents (median $=20$ ). Most poultry were kept under

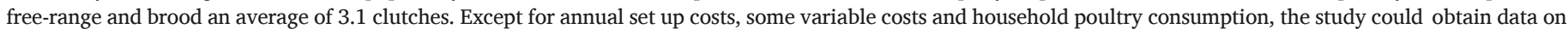

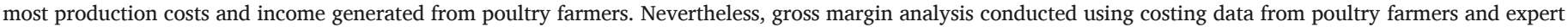

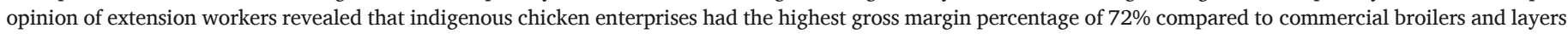

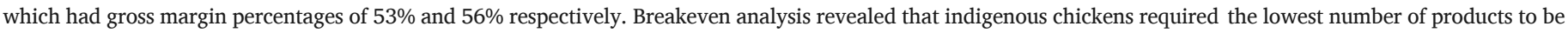

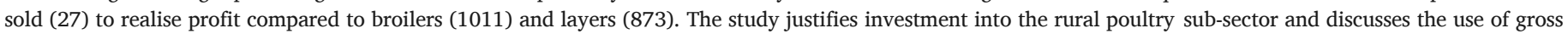
margin templates as a means of incentivising rural farmers to participate in extension programmes.
\end{abstract}

\section{Keywords:}

Rural poultry Financial

analysis Extension

programmes

Production costs

\section{Introduction}

Poultry contributes significantly to Asian and African food requirements (Dolberg, 2008; Alders et al., 2009). In sub-Saharan countries of Africa where food production is a challenge, rural poultry farming provides an affordable way of farming. When poultry farming is practised on a large scale and birds (fed on commercial feed) bred for high and quality meat or egg production, it is referred to as commercial poultry. When birds are kept on a small scale (usually with less than 100 birds), and mainly meant for domestic consumption, or when birds are meant for sale but reared with minimal resources (even if they are improved breeds), it is often referred to as rural poultry (Sonaiya, 2007; Akinola and Essien, 2011).

Within the rural poultry sector, there is indigenous poultry that comprises indigenous chickens, ducks and guinea fowl, which mostly scavenge for

feed with limited housing provided. Indigenous poultry production is common in rural communities in Zambia (Songolo and Katongo, 2000; Copland and Alders, 2009; Bwalya and Kalinda, 2014). That popularity is largely due to the low initial investment required and the purported resistance of indigenous poultry to some poultry diseases (Copland and Alders, 2009). In addition, indigenous poultry enterprises are more popular among socially disadvantaged groups like widows and orphaned children whose numbers are high in the region due to the Acquired Immune Deficiency Syndrome (AIDS) pandemic (Mutenje et al., 2008; Moreki and Dikeme, 2011; Simainga et al., 2011). On the other hand, indigenous poultry has a low feed to meat conversion ratio as well as low egg production which affects their profitability (Mtileni et al., 2012; Roberts, 2018). More expensive commercial broilers and layers have been introduced to rural poultry enterprises, and this change has increased demand for investment in the sector. Despite commercial breeds requiring more

\footnotetext{
* Corresponding author at: James Cook University, Queensland, 1 Solander Drive, QLD, 4812, Australia.

Email address: Chrisborn.mubamba@my.jcu.edu.au (C. Mubamba)
} 
investment, they have some advantages over indigenous chicken breeds because they have a higher feed to meat conversion ratio and take less time to reach market weight. Additionally, commercial layers lay more eggs in their productive life than indigenous chickens.

Despite its potential to contribute significantly to sub-Saharan economic growth, indigenous poultry is faced with numerous challenges such as mortality (Songolo and Katongo, 2000; Msoffe et al., 2010) and low productivity. The challenge of mortality may be addressed by veterinary services, but the issue of low productivity still poses a challenge for rural poultry farmers (Grace Lungu, Senior Animal Production Officer, Personal Communication). To improve productivity among the rural poultry sector, extension services need to innovate new strategies that will increase farmers competences and stimulate them to adopt new production technologies.

Unfortunately, extension service's investment into enhancing production in the rural poultry sector of developing countries like Zambia is low. This is partly because governments may believe funding other enterprises such as beef and dairy production provides greater financial gain than poultry (Mwacalimba, 2012). This bias is worsened by a male-dominated African society that traditionally believes funds spent on large livestock (which traditionally belong to men) is a better investment (Mwacalimba and Green, 2014). Thus, little work has been done by extension services in countries like Zambia, to evaluate the extension needs for the sector, which could help enhance and facilitate dialogue between service providers and farmers. As a result, most of the extension conducted in the sector has been a top down approach which has led to low adoption rates of sustainable poultry production strategies by rural poultry farmers (Yona Sinkala, Director of Veterinary Services, Personal Communication). Taking advantage of the fact that over $70 \%$ of rural households in this region keep poultry (GRZ, 2010), enhancing extension in the rural poultry sector would tap into the potential it has in increasing household income and food security among resource constrained households.

Farmers who embark on poultry production need to perform financial analysis to decide what kind of production system would suit them best. Financial analysis like gross margin and break-even analysis would inform farmers of the likely return on investment as well as how many products they need to produce for them to make profits in the production system they choose (Malcolm et al., 2005; McCown, 2005). If equipped with the ability to conduct financial analysis, farmers would then be able to choose whether to embark on indigenous, broiler or layer production depending on the availability of labour, material and financial resources. Unfortunately, most rural poultry farmers in countries like Zambia seem to lack this knowledge and thus just keep their poultry without realising whether they are making profit or not (Arthur Mumbolomena, Provincial Veterinary Officer, Personal communication). Furthermore, the problem of losses in poultry production may be masked by income obtained from other enterprises like crop production and gardening that could run concurrently within farming households thus creating a false impression of profits in a rural poultry business. This gap in knowledge among rural poultry farmers is among the main challenges that needs to be addressed by extension services using participatory extension approaches that stimulate interest and ensure full implementation by farmers.

As a sequel to the background above, a study which used production and financial data obtained from poultry farmers of Eastern Zambia, to describe the rural poultry sector and conduct financial analysis that compared the financial performance of indigenous chicken production to broiler and layer production was conducted. The aim of this study was to offer a practical tool for livestock extension officers to stimulate and enhance production among the rural poultry sector. It is recommended that rural farmers that have improved their production and need to upgrade to commercial farming, are referred to several existing publications that address productivity in commercial poultry farming.

\section{Materials and methods}

\subsection{Study area and description of the study population}

The study was conducted in the Eastern Province of Zambia (Fig. 1) from October 2014 to January 2015. For veterinary and livestock purposes, the Eastern Province of Zambia is divided into nine districts namely; Chipata, Chadiza, Katete, Lundazi, Mambwe, Petauke, Nyimba, Sinda and Vubwi (Fig. 1B). Districts are further divided into veterinary camps which are further divided into crush pen zones. Crush pen Zones are further divided into villages.

Volumes of poultry and its products that pass through different players of the value chain in some regions of Zambia have been described in other studies (Bwalya and Kalinda, 2014; Queenan et al., 2016). This study focusses on describing production and conducting financial analysis of rural poultry enterprises at the farm gate in the first year of inception to determine their viability as key poultry producers of Eastern Zambia. Thus, the study population comprised of rural poultry farmers of Eastern Zambia.

\subsection{Study design}

The study was conducted in two stages. The first stage involved collection of data on rural poultry production and raising systems, production and marketing costs as well as poultry mortality from rural poultry farmers using a structured questionnaire modified from those used in the Food Animals Biosecurity Network (FABN) project recently implemented in the southern Pacific Islands (Brioudes and Gummow, 2015). The questionnaire was administered by local veterinary assistants who received prior training in administering it. Some data obtained from the survey was then used as inputs in the financial analysis of broiler, layer and indigenous chicken enterprises in the next stage of the study.

\subsubsection{Sample size justification}

A sample of 459 poultry farmers were sampled within 200 villages and 40 veterinary camps from all the nine districts of Eastern Zambia in a poultry survey conducted from October 2014 to January 2015. The sample sizes were calculated according to Mubamba et al. (2018) (Table 1).

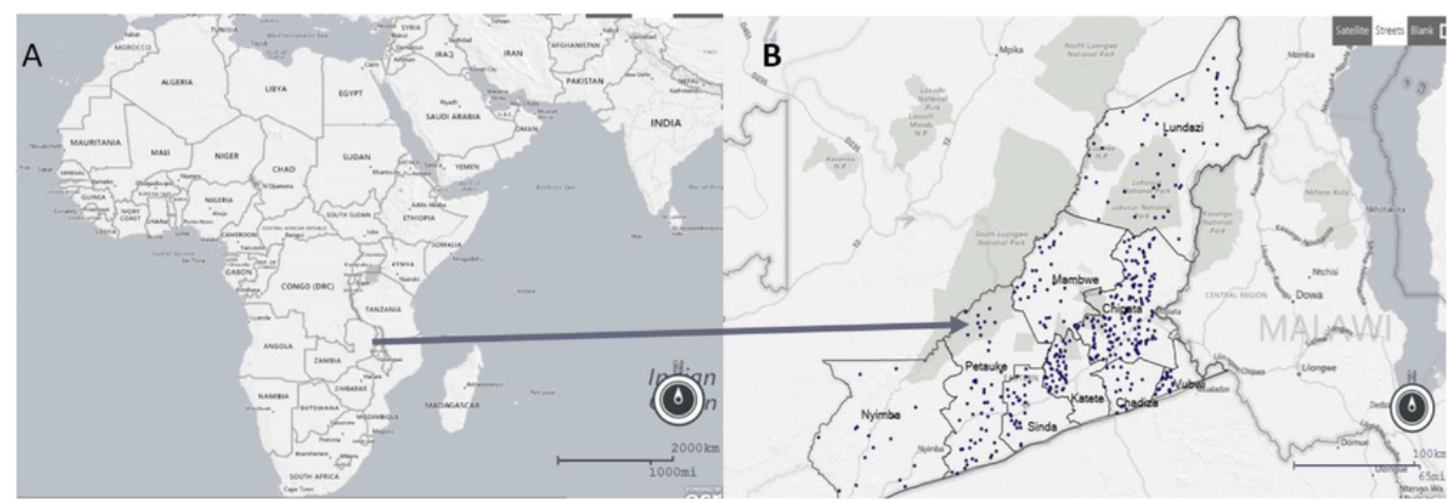

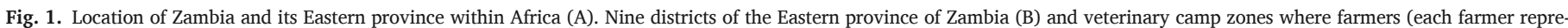
sented by a dot) were sampled within the province. Map obtained from Mubamba et al. 2018. 
Table 1

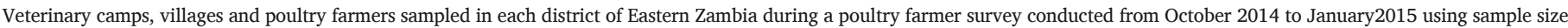
justification from Mubamba et al. (2018).

\begin{tabular}{|c|c|c|c|c|c|c|c|}
\hline District & $\begin{array}{l}\text { No. of } \\
\text { camps } \\
\text { (n) }\end{array}$ & $\begin{array}{l}\text { No. of } \\
\text { camps } \\
\text { sampled }\end{array}$ & $\begin{array}{l}\text { No. of } \\
\text { villages } \\
\text { sampled (5 } \\
\text { per camp) }\end{array}$ & $\begin{array}{l}\text { Median number of } \\
\text { poultry farming } \\
\text { households per } \\
\text { village }\end{array}$ & $\begin{array}{l}\text { No. of poultry } \\
\text { farming } \\
\text { households } \\
\text { sampled per } \\
\text { village }\end{array}$ & $\begin{array}{l}\text { Targeted sample of } \\
\text { poultry farming } \\
\text { households per } \\
\text { district }\end{array}$ & $\begin{array}{l}\text { Actual No. of } \\
\text { poultry farming } \\
\text { households sampled } \\
\text { per district }\end{array}$ \\
\hline Chipata & 18 & 11 & 55 & 63 & 3 & 165 & 172 \\
\hline Petauke & 9 & 5 & 25 & 39 & 2 & 50 & 49 \\
\hline Katete & 10 & 5 & 25 & 40 & 2 & 50 & 50 \\
\hline Lundazi & 9 & 5 & 25 & 45 & 2 & 50 & 56 \\
\hline Sinda & 8 & 4 & 20 & 37 & 2 & 40 & 37 \\
\hline Chadiza & 6 & 3 & 15 & 33 & 2 & 30 & 25 \\
\hline Vubwi & 1 & 1 & 5 & 72 & 4 & 20 & 18 \\
\hline Mambwe & 4 & 4 & 20 & 32 & 2 & 40 & 32 \\
\hline Nyimba & 3 & 2 & 10 & 40 & 2 & 20 & 20 \\
\hline Totals & 71 & 40 & 200 & & & 465 & 459 \\
\hline
\end{tabular}

\subsection{Study procedures and data analysis}

\subsubsection{Interviews}

An information sheet and consent form were provided to respondents before the commencement of interviews. After reading and understanding these documents, they were requested to sign the consent form. Interviews lasted approximately $80 \mathrm{~min}$ per respondent. GPS coordinates for all respondents were captured by the enumerators at the time of the interviews.

Information used for the study was derived from three sections of the questionnaire (general information, farm structure and poultry diseases) which gathered information on farmers' bio data and GPS coordinates, farm demographics, poultry reproduction, poultry mortality, poultry raising systems, poultry ranking versus other animals kept on the farms as well as monthly production and farm gate marketing costs including income derived from sales of poultry and its products. The questionnaire is available on request.

Where farmers failed to provide some information, expert opinion was sought from 5 extension workers who had worked closely with rural poultry farmers in the region for at least 3 years.

\subsubsection{Data storage}

Questionnaires with their associated tables were recreated and stored in Epi Info 7.2®. All data obtained from interviews was then entered and stored in this software as data base files. When needed for analysis, tables required were exported to Excel where they were merged, sorted and edited after which they were exported to required software packages for analysis.

\subsubsection{Data analysis}

2.3.3.1. Statistical analysis All questionnaire and expert opinion data was de identified to maintain confidentiality. IBM SPSS ${ }^{\circledR}$ version 24 was used to analyse quantitative and qualitative data. The median was used as the measure of central tendency because data was not normally distributed (Kolmogorov-Simonov test; $\mathrm{p}=0.001$ and the

Shapiro-Wilk test; $\mathrm{p}=0.001$ ). The Kruskal Wallis $\mathrm{H}$ test was used to analyse nonparametric when required. When differences were statistically significant, pairwise comparisons using Dunn's (1964) procedure with a Bonferroni adjustment (Laerd-Statistics, 2015) were used to pinpoint differences between respective groups. Qualitative data was analysed as frequencies for specific responses.

2.3.3.2. Spatial analysis Choropleth maps were used to indicate the median contribution of poultry income to households per district in eastern Zambia using Epi Map version 7.2. The data layer with median income obtained from poultry per district was added to shape files of eastern Zambia and its districts.

2.3.3.3. Financial analysis Financial analysis was conducted using gross margin analysis (GMA) that compared gross margin percentage (GMP) for the indigenous, broiler and layer chickens using production and costing information provided by poultry farmers in the survey and expert opinion from extension officers. The GMA was selected based on guidelines provided by Malcolm et al. (2005) and Rushton (2009).

2.3.3.3.1. Inputs for the analysis The following inputs obtained from the poultry farmer survey or expert opinion of extension workers were used for the financial analysis. Number of products sold per year was computed by multiplying the median monthly sales for each enterprise by 12 ( 1 unit $=1$ chicken or 1 tray of 30 eggs). Products Consumed by the household per year was calculated by multiplying the number of units sold per year by the proportion of products consumed and later dividing the product by the proportion of products that were sold. The proportion of poultry and products consumed annually was derived from the expert opinion and were 0.6 for indigenous chickens and 0.05 for both broilers and layers. Annual mortality rates for each chicken enterprise were obtained from the survey results. Mortality rates were calculated by dividing the number of respective poultry that died by the total stock of respective poultry groups. The unit price per product for each enterprise was the price of a live chicken, $1 \mathrm{~kg}$ of chicken meat or offal, 1 tray of 30 eggs and $1 \mathrm{~kg}$ of manure.

Setup costs (fixed costs) included costs of poultry equipment like feeders and drinkers and those for infrastructure. Set up costs were obtained from expert opinion of extension workers. To account for depreciation, the residue value of setup costs after 3 years was used in the break-even analysis. It was computed by subtracting annual depreciation from initial set up costs for each poultry enterprise. Depreciation for setup costs was estimated at $20 \%$ over 3 years. A period of 3 years was selected because it is assumed to be the time it takes for most rural enterprises to start running sustainably in Eastern Zambia (Grace Lungu, Senior Livestock Production Officer, Personal Communication). Variable costs included costs that rise proportionally to a rise in production. These included costs for procuring chicken stock, chicken feed, veterinary, labour and farmgate marketing costs obtained from the survey and expert opinion. Farmgate costs included advertising and costs of some packaging materials such as trays for eggs. Monthly variable costs and income derived from questionnaire results were converted to annual values by multiplying them by 12 .

2.3.3.3.2. Gross margin analysis Broiler and Layer production were compared to indigenous chicken production as a model species for indigenous poultry enterprises within the province using GMP. Gross margin percentage for each enterprise was computed using a process that computed the following parameters. Annual Enterprise Output (AEO) included the total value of poultry and poultry product sales including the value of poultry and products that were consumed by households during the year. The annual poultry sales were computed by multiplying number of products sold per year by the sales price. The value of the poultry consumed was calculated by multiplying the number of poultry consumed per year by the sale price of a respective product unit for each respective enterprise. Annual Variable Costs (AVC) included the total of variable costs incurred per year. The annual Gross Margin (GM) was computed by subtracting AVC from AEO (GM = AEO-AVC). Gross Margin Percentage (GMP) was finally computed by dividing GM by AEO. The enterprise with the 
highest GMP was then identified as the most financially effective in the first year of inception and vice versa.

2.3.3.3.3. Break-even analysis Breakeven analysis (Malcolm et al., 2005; Cafferky, 2010) was performed to determine how many product units each enterprise needed to sell to recover its costs and start realizing profit. This in turn would help assess which enterprise required the list number of product units to breakeven and thus be more practical to manage by rural poultry farmers whose financial and material resources for investments are usually low or non-existent. The analysis was conducted using the following steps and variables.

Sale Price Per Product was obtained from the survey results (Table 3 ). Fixed costs included residual costs of setup costs, labour costs and veterinary costs. In this analysis, labour and veterinary costs were regarded as semi fixed costs.Variable costs per product unit were then computed from total variable costs by dividing annual variable cost by respective number of products sold annually for each respective enterprise. The unit contribution margin represents how much money each unit sold brings in after recovering its own variable costs. It was calculated by subtracting a unit's variable costs from its sales price for each respective enterprise. The contribution margin ratio gives a percentage that can be used to determine the profits that will result from various sales levels. The contribution margin ratio was calculated by dividing the unit contribution margin by sales price per product. The enterprise break-even point, which tells the volume of sales to be achieved to cover all the costs was finally calculated by dividing set up costs by the respective unit contribution margin.

\section{Results}

Results of the study are presented as an overview of the survey and expert opinion results in 3.1 followed by results of the financial analysis in 3.2 .

\subsection{Survey and expert opinion results}

\subsubsection{General information}

A total of 459 poultry farmers were interviewed across eastern Zambia. Among these, 169 (36.8\%) were female and 290 (63.2\%) were male. Their average poultry farming experience was 14 years (SD = 11.79 , range $0-55$ ). Only fourteen percent of farmers had no education background while $60 \%, 22 \%$, and $1 \%$ attained primary, secondary and tertiary education respectively.

\subsubsection{Farm demographics}

Overall, the median number of chickens per farmer was 20 (Median $=20$, range 1-465). For farmers that kept ducks, guinea fowls, pigeons and other poultry species, the median per household was 6 (range 1-61), 6 (range 2-32), 19 (range 1-423) and 8 (range 2-41) respectively.

For flock composition, indigenous chickens were the most common poultry type among all age groups of poultry with compositions of 88.3, 87.4, 83.6 and $79.5 \%$ for chicks, pullets, cockerels, and hens within each age group of poultry (not segregated by poultry type) respectively. Overall median flock composition across all poultry types was 8, 5, 2 and 5 chicks, pullets, cockerels and hens per household respectively.

\subsubsection{Reproduction in rural poultry}

Indigenous chickens brood at a median of 3 clutches (range 1-6) of 7-18 eggs (Songolo and Katongo, 2000) per year while of commercial broiler and layers produce an average of 140 eggs per year with a 92-94\% fertility (FAO, 2003).

\subsubsection{Mortalities in rural poultry}

Mortality rates for indigenous chickens, broilers, and layers were computed at 45\%, 15\%, 5\% per year respectively.

\subsubsection{Farm poultry raising systems}

The main poultry raising system used by farmers was free range ( $80.1 \%$ of responses) followed by a semi intensive traditional system grain left overs ( $14.1 \%$ of responses). The large-scale system which involves advanced housing and intensive feeding of poultry with commercial feeds only received $5.4 \%$ of the responses. Lastly, other systems not described above only received $0.4 \%$ of responses.

\subsubsection{Poultry ranking versus other animals kept on farms}

Poultry ranked highest in terms of popularity and numbers when compared with other animals kept by respondents (mean $=43$ birds per household, $\mathrm{SD}=101.9$, percentage of total livestock $=64.5 \%)$. Cattle and pigs followed with total livestock percentages of $14.4 \%$ and $6.7 \%$ respectively. Overall, the average number of livestock units owned by each farming household or farm was 16. A livestock unit represented one domestic animal regardless of species and breed.

\subsubsection{Production and marketing costs for rural poultry}

About $73.6 \%$ of poultry farmers interviewed were not aware of production costs for their poultry while only $22.4 \%$ were aware. Approximately $3.9 \%$ of respondents did not respond to this question. Results derived from informed farmers revealed that the median monthly cost for purchase of chicken and feed per household was 500 Zambian Kwacha (ZMW), ZMW 60 for treatment costs and ZMW 45 for other costs. At the time of the survey ZMW 1 was equivalent to 0.17 United States dollars (USD). Layer production was the costliest (median cost for chicks feed and housing = ZMW 750, treatment costs = ZMW 225 and other costs $=$ ZMW 63.89) followed by broilers (median cost for chicken feed $=$ ZMW 583, treatment costs = ZMW 63). Production costs for indigenous chickens were at a monthly median of ZMW 20 for chicks and stock feed, and ZMW 30 for treatment costs.

Since farmers were only able to provide a combined amount on what they spent on the purchase of stock (chicks, pullets, hens, etc.) and feed, a short follow-up interview of 5 local extension officers was conducted to estimate what proportion of this amount would specifically consist of feed costs and stock costs. The most frequent response was that $70 \%$ of the combined amount consisted of feed costs. Thus, estimated feed costs were computed as ZMW 525, ZMW 408 and ZMW 14 per month for layers, broilers, and indigenous chickens respectively, while estimated costs of stock were ZMW 225, ZMW 175, and ZMW 6 respectively.

Poultry farmers were also unable to estimate set up costs, some variable costs like labour and marketing costs as well as the proportion of poultry they consumed per year for each enterprise. Thus, expert opinion, whose results are summarised in Table 2 was sought from 5 local extension officers to estimate these costs.

\subsubsection{Income from rural poultry}

Among poultry farmers, $56.4 \%$ of them said they sold their poultry while $41.6 \%$ did not. Two percent of respondents did not give a response to this prompt. Furthermore, $45.8 \%$ of farmers were aware of how much monthly income they derived from the sale of poultry while $50.1 \%$ were not and $4.1 \%$ did not give a response. Income from poultry enterprises contributes an average of

Table 2

Median and range (in brackets) of annual own household poultry consumption, set up costs and some variable costs for indigenous, broiler and layer chicken production per flock in Eastern Zambia according to the expert opinion provided by extension workers during a survey conducted from October 2014 to January 2015.

\begin{tabular}{llll}
\hline Item & Indigenous & Broilers & Layers \\
\hline $\begin{array}{l}\text { Proportion of } \\
\text { poultry and }\end{array}$ & 0.6 & 0.05 & 0.05 \\
products consumed & $(0.5-0.8)$ & $(0.03-0.10)$ & $(0.02-10)$ \\
$\begin{array}{l}\text { Infrastructure costs } \\
\text { (ZMW) }\end{array}$ & 85 & 9000 & 11,000 \\
$\begin{array}{l}\text { Cost of equipment } \\
\text { (ZMW) }\end{array}$ & $(50-150)$ & $(5000-27000)$ & $(8500-32000)$ \\
$\begin{array}{l}\text { Farmgate marketing } \\
\text { costs per unit }\end{array}$ & 0.05 & 5000 & 5000 \\
$\begin{array}{l}\text { (ZMW) } \\
\text { Labour hours per }\end{array}$ & $(0.01-0.10)$ & $(250-6000)$ & $(650-8000)$ \\
day & 0.25 & $(0.10-0.50)$ & 0.8 \\
\hline
\end{tabular}


Table 3

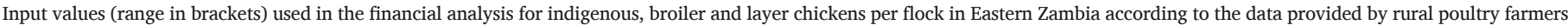
and expert opinion of extension workers in a survey conducted from October 2014 to January 2015

\begin{tabular}{|c|c|c|c|c|}
\hline Item & Indigenous & Broiler & Layer & Comments/ data source \\
\hline \multicolumn{5}{|l|}{ Production and Health data } \\
\hline Units produced \& sold ${ }^{\mathrm{a}}$ & $36(12-54)$ & $1260(24-2340)$ & $1116(9-1853)$ & Obtained from questionnaire results \\
\hline $\begin{array}{l}\text { Proportion of units produced } \\
\text { and consumed }\end{array}$ & $0.6(0.5-0.8)$ & $\begin{array}{l}0.05 \\
(0.03-0.10)\end{array}$ & $0.05(0.02-10)$ & Expert opinion from extension workers \\
\hline Mortality & $\begin{array}{l}0.45 \\
(0.25-0.55)\end{array}$ & $\begin{array}{l}0.15 \\
(0.02-0.37)\end{array}$ & $0.05(0.01-0.23)$ & Obtained from questionnaire results \\
\hline $\begin{array}{l}\text { Farm gate sale price per unit } \\
\text { (ZMW) }\end{array}$ & $25(15-30)$ & $25(20-35)$ & $30(27-35)$ & Obtained from questionnaire results \\
\hline \multicolumn{5}{|l|}{ Set up costs (ZMW) } \\
\hline Infrastructure costs & $85(50-150)$ & $\begin{array}{l}9000 \\
(5000-27000)\end{array}$ & $\begin{array}{l}11,000 \\
(8500-32000)\end{array}$ & Expert opinion from extension workers \\
\hline Feeders and drinkers & $45(30-60)$ & $\begin{array}{l}5000 \\
(250-6000)\end{array}$ & $\begin{array}{l}5000 \\
(650-8000)\end{array}$ & Expert opinion from extension workers \\
\hline \multicolumn{5}{|l|}{ Variable costs (ZMW) } \\
\hline Stock costs per bird & $2.0(1.2-3.8)$ & $1.7(1.7-5.9)$ & $2.4(2.1-4.3)$ & Obtained from questionnaire results \\
\hline Feed Costs per bird & $4.7(4.2-5.9)$ & $3.9(3.5-4.8)$ & $5.6(4.1-6.4)$ & Obtained from questionnaire results \\
\hline $\begin{array}{l}\text { Vet costs per } 1000 \text { batch of } \\
\text { birds }^{\text {b }}\end{array}$ & $30(5-442)$ & $63(40-3000)$ & $225(50-9950)$ & Obtained from questionnaire results \\
\hline Labour costs per day & $\begin{array}{l}1.0 \\
(0.20-0.50)\end{array}$ & $\begin{array}{l}21.6 \\
(3.00-8.00)\end{array}$ & $14.4(1.50-8.00)$ & $\begin{array}{l}\text { Expert opinion from extension workers and Zambian government } \\
\text { labour law rate of } 3.6 \mathrm{ZMW} \text { per hour. }\end{array}$ \\
\hline $\begin{array}{l}\text { Farmgate marketing costs per } \\
\text { unit }\end{array}$ & $\begin{array}{l}0.05 \\
((0.01-0.10)\end{array}$ & $0.4(0.01-0.10)$ & $0.8(0.40-2.50)$ & Expert opinion from extension workers \\
\hline
\end{tabular}

a 1 product unit $=1$ live chicken, $1 \mathrm{~kg}$ of chicken carcass or offal, and 1 tray of 30 eggs.

b Since most vet drugs and vaccines are packaged in doses of 1000 , vet costs were assumed to be doubling when the products exceed 1000,2000 etc.

$30 \%$ to the total household income (median $=20 \%$, minimum $=10 \%$, maximum $=100 \%)$.

High poultry income districts were Katete, Petauke, Chadiza and Vubwi with median poultry income contributions to overall household income of $30 \%$ and above (Fig. 2). On the other hand, Lundazi, Mambwe, Chipata, Sinda and Nyimba districts were medium poultry income districts with median poultry income contribution to overall household income ranging from 10 to $20 \%$ (Fig. 2). There was no low poultry income district (median poultry income contribution less than $10 \%)$. Differences in median income between high and medium poultry income districts were statistically significant (Kruskal Wallis test; $\mathrm{p}$ $=0.001$ and all pairwise comparisons with Bonferroni adjustment between high and low poultry income districts $\mathrm{p}=0.001$ )

Overall median monthly income derived from poultry sales was ZMW 80 per household. Highest median income was from layers followed and indigenous chickens with median values of ZMW 2793, ZMW 2500 and ZMW 75 respectively. From this data, number of units sold per month was computed as 93, 100 and 3 for layers, broilers, and indigenous chickens, based on prices of ZMW 25 and ZMW 30 for 1 chicken and 1 tray of eggs, provided by farmers.

\subsection{Financial analysis of rural poultry enterprises}

\subsubsection{Inputs for the analysis}

Table 3 shows poultry production and income data obtained from the farmer survey and expert opinion that was used to compute inputs for the annual gross margin and break-even analysis.

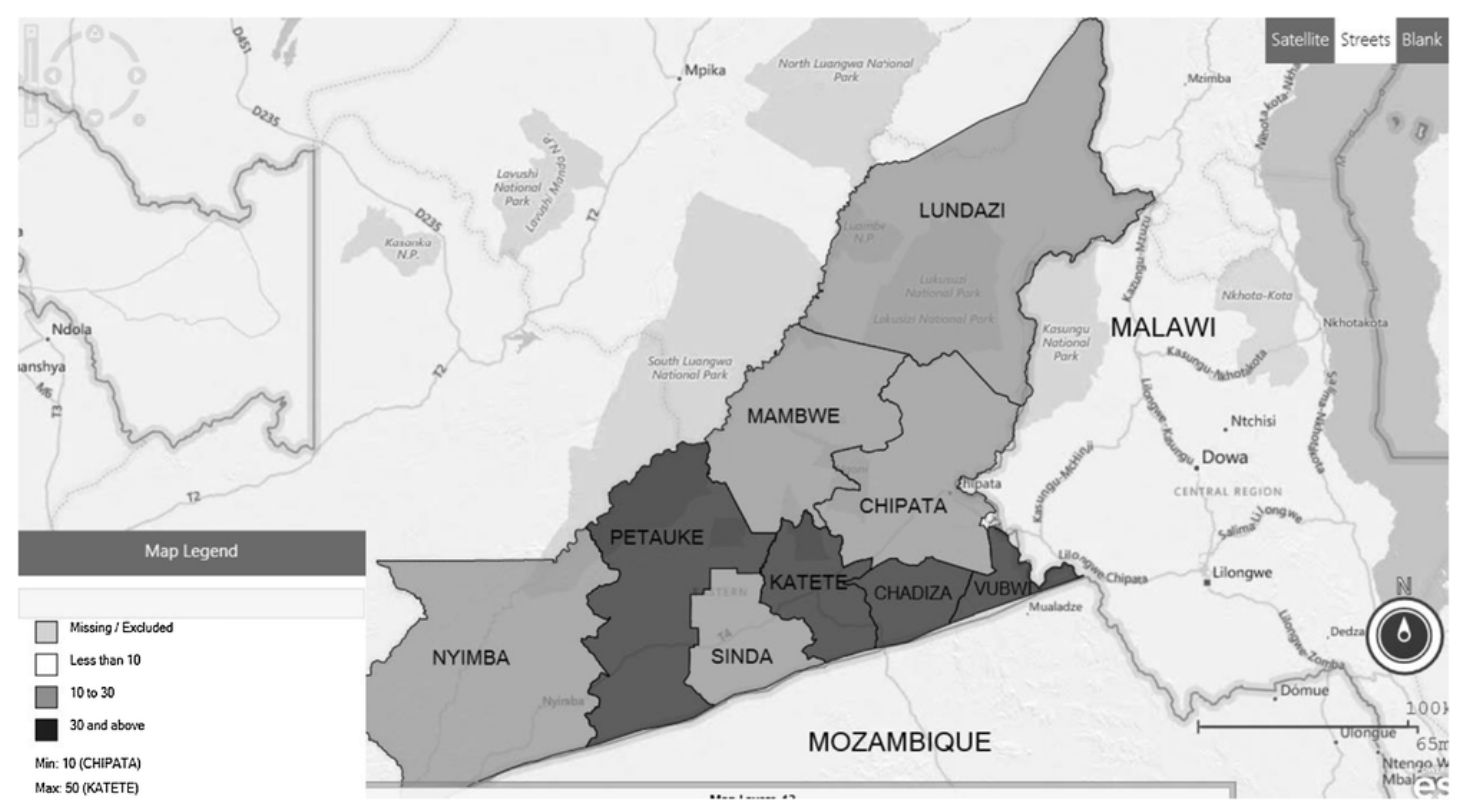

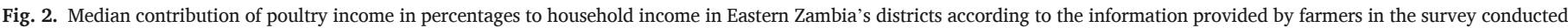
from October 2014 to January 2015. 


\subsubsection{Gross margin analysis}

When GMA was conducted using production and costing information which was provided by farmers and extension officers, indigenous chicken enterprises had the GMP of $72 \%$ compared to commercial broilers and layers which had GMP of 53\% and 56\% respectively (Table 4).

\subsubsection{Break-even analysis}

Breakeven analysis results revealed that indigenous chickens required the lowest number of products sold to breakeven in the first year of inception (27) followed by layers (873) and broilers (1011) (Table 5).

\section{Discussion}

The sampling strategy used to select farmers could affect the accuracy of results for this study. This is because the exact number of villages per camp could not be obtained and thus it was estimated. More still sampling depended on sampling frames provided by village headmen at the village. Village head-

\section{Table 4}

Gross margin analysis for the indigenous, broiler and layer chicken enterprises per flock in the first year of inception in Eastern Zambia, according to data obtained from the poultry farmers and extension workers during a survey conducted from October 2014 to January 2015.

\begin{tabular}{|c|c|c|c|}
\hline & $\begin{array}{l}\text { Indigenous } \\
\text { Chickens }\end{array}$ & Broilers & Layers \\
\hline \multicolumn{4}{|l|}{ A. Enterprise outputs } \\
\hline $\begin{array}{l}\text { Sale of poultry and } \\
\text { its products }\end{array}$ & ZMW 900.00 & $\begin{array}{l}\text { ZMW } \\
31,500.00\end{array}$ & $\begin{array}{l}\text { ZMW } \\
33,480.00\end{array}$ \\
\hline $\begin{array}{l}\text { Consumed poultry } \\
\text { and its products }\end{array}$ & ZMW 1350.00 & $\begin{array}{l}\text { ZMW } \\
1657.89\end{array}$ & $\begin{array}{l}\text { ZMW } \\
1762.11\end{array}$ \\
\hline Total outputs & ZMW 2250.00 & $\begin{array}{l}Z M W \\
33,157.89\end{array}$ & $\begin{array}{l}Z M W \\
35,242.11\end{array}$ \\
\hline \multicolumn{4}{|l|}{ B. Enterprise inputs } \\
\hline Annual stock costs & ZMW 72.00 & $\begin{array}{l}\text { ZMW } \\
2142.00\end{array}$ & $\begin{array}{l}\text { ZMW } \\
2678.40\end{array}$ \\
\hline Annual feed Costs & ZMW 169.20 & $\begin{array}{l}\text { ZMW } \\
4914.00\end{array}$ & $\begin{array}{l}\text { ZMW } \\
6249.60\end{array}$ \\
\hline Annual vet costs & ZMW 30.00 & $\begin{array}{l}\text { ZMW } \\
126.00\end{array}$ & $\begin{array}{l}\text { ZMW } \\
450.00\end{array}$ \\
\hline $\begin{array}{l}\text { Annual farmgate } \\
\text { marketing costs }\end{array}$ & ZMW 1.80 & $\begin{array}{l}\text { ZMW } \\
504.00\end{array}$ & $\begin{array}{l}\text { ZMW } \\
892.80\end{array}$ \\
\hline Annual labour costs & ZMW 365.00 & $\begin{array}{l}\text { ZMW } \\
7884.00\end{array}$ & $\begin{array}{l}\text { ZMW } \\
5256.00\end{array}$ \\
\hline Total inputs & ZMW 638.00 & $\begin{array}{l}Z M W \\
15,570.00\end{array}$ & $\begin{array}{l}Z M W \\
15,526.80\end{array}$ \\
\hline C. Gross Margin & ZMW 1612.00 & $\begin{array}{l}\text { ZMW } \\
17,587.89\end{array}$ & $\begin{array}{l}\text { ZMW } \\
19,715.31\end{array}$ \\
\hline $\begin{array}{l}\text { D. Gross Margin } \\
\text { Percentage }\end{array}$ & 71.64 & 53.04 & 55.94 \\
\hline
\end{tabular}

\section{Table 5}

Breakeven analysis for the indigenous, broiler and layer chicken enterprises per flock in Eastern Zambia according to the data provided by poultry extension workers during a survey conducted from October 2014 to January 2015.

\begin{tabular}{llll}
\hline & $\begin{array}{l}\text { Indigenous } \\
\text { chickens }\end{array}$ & Broilers & Layers \\
\hline $\begin{array}{l}\text { Farmgate sale price } \\
\text { per unit }\end{array}$ & ZMW 25.00 & ZMW 25.00 & ZMW 30.00 \\
$\begin{array}{l}\text { Fixed costs } \\
\text { Variable costs per }\end{array}$ & ZMW 499.00 & ZMW & ZMW \\
$\begin{array}{l}\text { unit } \\
\begin{array}{l}\text { Unit contribution } \\
\text { margin }\end{array}\end{array}$ & ZMW 18.25 & ZMW 6.00 & ZMW 8.80 \\
$\begin{array}{l}\text { Contribution } \\
\text { margin ratio }\end{array}$ & 0.7 & ZMW 19.00 & ZMW 21.20 \\
Break Even Point & $\mathbf{2 7}$ & 0.8 & 0.7 \\
\hline
\end{tabular}

men could possibly miss out some poultry farmers due to selection and memory bias. To counter part of this weakness, interviewers were instructed to conduct interviews on farm for verification of farmers as viable poultry farmers and they were also requested to ask respondents whether they knew any other poultry farmers within their village to ensure that other farmers were not missed.

Accuracy of data provided by farmers could have been affected by misclassification and memory bias among respondents (Schacter, 1999). Misclassification and memory bias were not accounted for in this study. Nevertheless, most poultry farmers (86\%) in this study had some form of education, which implies that most of them had the ability to understand the questionnaire and provide accurate responses. Furthermore, to counter possible memory and selection bias, medians were used to compute data obtained from questionnaires and expert opinion. The other reason medians were used was because the data were not normally distributed. Using averages for inputs would have led to more biased computed return on investment values thus leading to exaggerated conclusions as averages are significantly affected by extreme values (Cockroft and Holmes, 2003; Sheskin, 2003).

Expert opinion data on poultry and products consumed by households, start-up, labour and marketing costs could also affect the accuracy of financial analysis. This is because it was obtained from extension workers rather than the actual poultry farmers who conduct poultry farming. The possibility of this bias was however minimised by only obtaining expert opinion from extension workers who had extensive experience and worked within the communities with the poultry farmers.

Despite the highlighted weaknesses, this study reveals key poultry production information which could be utilised by government extension services as well as the poultry industry, including farmers, in planning, implementation and monitoring of their programs. Extension officers could use production and financial analysis data to enhance extension services and lobby for increased funding to the rural poultry sector by government. Disease control planners could use this production data to set baseline and targets for implementing disease control activities like mass vaccination and disease awareness campaigns.

Survey results indicate that poultry ranks highly among livestock kept by rural farmers. Secondly, it contributes significantly to the rural households' monthly income with an average of $30 \%$ of their income. Despite its popularity, indigenous poultry is not adequately considered for funding by government agricultural extension and livestock disease control agencies because they prioritise cattle and other large livestock perceived to be more economically important (Mwacalimba and Green, 2014). This study, nevertheless shows how popular poultry farming is among rural farming households and provides justification why veterinary and extension services should enhance the quality of their extension delivery methodologies for this subsector.

The level of poultry income contribution to the overall rural household income may indirectly indicate importance attached to poultry farming in respective regions. These areas need to be prioritised when planning for disease control and rural poultry production enhancement projects because increased funding for rural poultry in such regions may have greater socioeconomic impacts and vice versa. According to the survey results of this study, Petauke, Katete, Chadiza and Vubwi districts are high poultry income districts (Fig. 2), and hence need to be prioritised for rural poultry development.

The current stocking level of poultry in indigenous chickens is adequate for realising a positive return on investment in the first year of inception (Table 4). More still, indigenous chickens are more practically possible to rear for rural farmers who are challenged with resources for setting up a viable poultry enterprise because they require less production costs than broilers and layers (Mack et al., 2005; Akinola and Essien, 2011). Viability of indigenous chickens in this study was further demonstrated by the low breakeven point which implies fewer indigenous chickens need to be produced to realise a positive gain on investment compared to broilers and layers (Table 5). Extension officers can use these results to demonstrate the viability of the indigenous chickens to rural farmers.

Bearing in mind that $74 \%$ of poultry farmers in this study were unable to provide costs for their poultry enterprises, extension workers 
weakness to initiate open information sharing sessions with farmers by introducing a simple GM analysis. Since all the farmers were unable to provide set up costs and some variable costs such as marketing and labour costs, attention can be given to these items as an example. To encourage participation and ownership of the budgeting lessons among farmers, extension workers would need to act as moderators rather than teachers. The plausibility of this approach is further supported by the fact that most poultry farmers interviewed in the survey had some form of education and experience (general information), thus implying most of them had sufficient numeracy and literacy skills that are required to fully participate in budgeting discussions.

Gross margin analysis was preferred over other conventional farm management, enterprise and business analysis techniques such as input and output analysis, enterprise budgets and whole-farm budgets because GMA would assist farmers to determine and monitor the performance of their business without accounting for fixed costs(Rushton, 2009). Thus GMA would indicate the profit farmers would get from each poultry production systems that could be used for paying off loans used to acquire capital assets and other long term investments (Malcolm et al., 2005). GMP is also used to compare the financial performance of different related enterprises (McCown, 2005; Rushton, 2009). Thus, in this study, GMP provided greater detail for farmers to understand the financial performance of their indigenous, broiler and layer chickens in a more practical and simpler manner (Table 4). On the other hand, the breakeven analysis demonstrated the level of production needed for each enterprise to pay off the fixed costs and still make profit. Bearing in mind that rural poultry farmers are resource constrained, the enterprise with the lowest breakeven point also indirectly indicates the most practical or viable enterprise for the rural poultry farmers since it required less products to breakeven. Thus, indigenous chickens were the most viable poultry enterprise for the rural farmers (Table 5).

Open information sharing sessions on GM budgets with poultry farmers would provide a foundation for leading them into discussing more complex financial analysis. An example of such analysis is the discounted cash flow (Malcolm et al., 2005; McCown, 2005; Rushton, 2009) which would assess the performance of the enterprises over several years in which repayment of capital investments including interests is spread over years and assigned a present value. This would in turn assist in assessing the value for the money that is spent on the three poultry production systems.

One way to increase farmers' consciousness to poultry mortality is by demonstrating its cost implications on their enterprises. Conducting GMA with a scenario where mortality rates for the indigenous, broiler and layer chickens were set at zero, would provide an opportunity to sensitize farmers to the importance of reducing poultry mortality in their flocks. This could then be followed by encouraging poultry farmers to use vaccinations as a mitigation measure for the problem. As a result, this could arouse farmers' interest in developing a vaccination calendar with an extension worker that relates the time of reproductive activity of indigenous chickens with important vaccinations. For instance, results of this study revealed that indigenous chickens had an average of three clutches per year. Thus, to ensure that all generations of chickens are adequately covered with ND vaccinations should be carried out three times in a year. This is in line with the current strategy where ND vaccinations are recommended three times per year (Alders et al., 2002) as opposed to the current trend where ND vaccination in indigenous chickens are mostly done twice per year (Personal observation). Such an extension strategy could significantly reduce mortality rate in indigenous chickens which currently stands at 0.45 .

Demonstration of a GMA scenario with mortality set at $0 \%$ may also arouse farmers' interest in analyzing cost implications of other production and health challenges among their flocks. Taking advantage of this opportunity, more open sharing sessions which identify, and analyses costs of possible challenges could be facilitated by the extension provider. Additionally, the extension provider may stimulate more interest by adding some of the documented challenges for rural poultry production to a list of those identified by farmers. Other than diseases, predation, malnutrition and extreme environmental conditions, have been previously identified as challenges leading to mortality (Harrison and Alders, 2010). Other challenges to rural poultry production in- clude weight loss and drop in egg production (Harrison and Alders, 2010; Mtileni et al., 2012).

Farmers are known to make decisions based on their values and priorities and these values may vary between farmers and between members of a family (Gamble et al., 2003). They may make such decisions based on their subjective beliefs with those beliefs heavily dependent on their own experience (McCown, 2005). Thus, financial assessments like GMA and break-even analysis can be promoted by extension providers as tools for providing advice to rural poultry farmers as ultimate decision makers on the farm. This is because GM budgeting and breakeven analysis provide a systematic approach to a decision that includes development of a clear outcome to be achieved by the decision through development of models that build links between the decision and the desired outcome.

\section{Conclusion and recommendations}

Description and financial analysis of the rural poultry enterprises using information provided by rural farmers can be used to reveal opportunities and knowledge gaps among farmers that could be utilised by extension services to enhance service delivery in the rural poultry sector. Findings of this study further provide key information for the rural poultry sector, to extension services within Zambia and other similar developing regions. This information is needed by these institutions to set targets during planning, implementation and monitoring of their rural poultry extension programmes.

\section{Ethical consideration}

Permission to do this study was obtained from the Departments of Veterinary and Livestock Development, Ministry of Agriculture and Livestock in Zambia. The study was approved by the Human Research Ethics Committee of James Cook University (Application ID; H5830).

\section{Acknowledgements}

The study was funded by Australian Awards (OASIS ID: STOOOK8) and James Cook University, Australia, with contributions from the National Research Foundation in Pretoria, South Africa. The authors acknowledge D. Chilembo, C. Hapoma, C. Moono, E. Kafundanga, P. Mwango, N. Mulombwaluse, N. Alibandila, J. Ngambi, C. Mainza, J. Kabucha, W. Sinyangwe, N. Bilima, E. Sinzala and K. Mbumwae for their role in data collection and entry. Additionally, Dr A. Mumbolomena, Dr M. Sinzala, Mr J. Sikazindu and Ms M. Mwanza from the veterinary department as well as Mr D. Phiri from Petauke district council in Zambia are also recognised for their numerous contributions towards the success of this study.

\section{References}

Akinola, L.A.F., Essien, A., 2011. Relevance of rural poultry production in developing countries with special reference to Africa. Worlds Poult. Sci. J. 67, 697-705.

Village chickens, poverty alleviation and the sustainable control of Newcastle disease. In: Tanzania, 5-7 October 2005. ACIAR Proceedings No. 131. Proceedings of an International Conference Held in Dar Es Salaam p. 2009. 235.

Bwalya, R., Kalinda, T., 2014. An analysis of the value chain for indigenous chickens in Zambia's Lusaka and Central provinces. J. Agric. Stud. 2, 31-52.

Cafferky, M., 2010. Breakeven Analysis: the Definitive Guide to Cost-volume-profit Analysis. Business Expert Press.

Cockroft, P.D., Holmes, M.A. (Eds.), 2003. Handbook of Evidence-Based Veterinary Medicine. Blackwell Publishing.

Copland, J.W., Alders, R.G., 2009. The comparative advantages of village or smallholder poultry in rural development. In: Alders, R.G., Spradbrow, P.B., Young, M.P. (Eds.), Village Chickens, Poverty Alleviation and the Sustainable Control of Newcastle Disease Proceedings of an International Conference Held in Dar Es Salaam Tanzania. p. 235, 5-7 October 2005. ACIAR Proceedings No. 131.

Dolberg, F., 2008. Poultry production for livelihood improvement and poverty alleviation. Bangkok, November 2007.. Proceedings of the International Conference Poultry in the Twenty-First Century: Avian Influenza and Beyond. Proceedings of an International Poultry Conference[Online] Available: ftp://ftp.fao.org/docrep/fao/011/ i0323e/i0323e.pdf.

FAO, 2003. Egg Marketing: a Guide for the Production and Sale of Eggs. FAO Agricultural Services Bulletin, 150. 
Gamble, D., Blunden, S., Ramsay, G., 2003. Sustaining the family farm: an integrated approach linking social, business and environmental aspects. RIRDC, Toowoomba, Queensland. First Australian Farming Systems Conference 4.

GRZ, 2010. In: CSO (Ed.), Census of Population and Housing, Agriculture Analytical Report, Lusaka.

Harrison, J.L., Alders, R.G., 2010. An assessment of chicken husbandry including Newcastle disease control in rural areas of Chibuto, Mozambique. Trop. Anim. Health Prod. 42, 729-736.

Laerd-Statistics, 2015. Kruskal-Wallis H Test Using SPSS Statistics. Statistical Tutorials and Software Guides. Retrieved from https://statistics.laerd.com/.

Mack, S., Hoffmann, D., Otte, J., 2005. The contribution of poultry to rural development. Worlds Poult. Sci. J. 61, 7-14.

Malcolm, B., Makeham, J., Wright, V., 2005. The Farming Game: Agricultural Management and Marketing. Cambridge University Press.

McCown, R.L., 2005. New thinking about farmer decision makers. In: Hatfield, J.L. (Ed.), The Farmer's Decision: Balancing Economic Successful Agriculture Production With Environmental Quality. Soil and Water Conservation Society, Ankeny, Iowa, USA, pp. $11-44$.

Moreki, J.C., Dikeme, R., 2011. Small Livestock, Food Security, Nutrition Security and HIV/AIDS Mitigation. [Online] Available: http://www.intechopen.com/download/ pdf/pdfs_id/22357.

Mtileni, B.J., Muchadeyi, F.C., Maiwashe, A., Chimonyo, M., Mapiye, C., Dzama, K., 2012. Influence of socioeconomic factors on production constraints faced by indigenous chicken producers in South Africa. Trop. Anim. Health Prod. 45, 67-74.

Mubamba, C., Ramsay, G., Abolnik, C., Dautu, G., Gummow, B., 2018. Is syndromic data from rural poultry farmers a viable poultry disease reporting tool and means of identifying likely farmer responses to poultry disease incursion?. Prev. Vet. Med. 153, 84-93.

Mutenje, M.J., Mapiye, C., Mavunganidze, Z., Mwale, M., Muringai, V., Katsinde, C.S., Gavumende, I., 2008. Livestock as a buffer against HIV and AIDS income shocks in households of Zimbabwe. Dev. South. Afr. 25 (1), 75-82. https://doi.org/10.1080/ 03768350701837754 .

Mwacalimba, K.K., 2012. Globalised disease control and response distortion: a case study of avian influenza pandemic preparedness in Zambia. Crit. Public Health 22, 391-405.

Mwacalimba, K.K., Green, J., 2014. 'One health' and development priorities in resource-constrained countries: policy lessons from avian and pandemic influenza preparedness in Zambia. Health Policy Plan. 1.

Queenan, K., Alders, R., Maulaga, W., Lumbwe, H., Rukambile, E., Zulu, E., Bagnol, B., Rushton, J., 2016. An appraisal of the indigenous chicken market in Tanzania and Zambia. Are the markets ready for improved outputs from village production systems?. Livest. Res. Rural Dev. 28, 10.

Roberts, J.A., 2018. Utilisation of Poultry Feed Resources by Smallholders in the Villages of Developing Countries (available online (undated.)). FAO Document Repositoryhttp: //www.fao.org/docrep/004/AC154E/AC154E12.htm.

Rushton, J., 2009. The Economics of Animal Health and Production. Cabi, Wallingford, UK.

Sheskin, D.J., 2003. In: Handbook of Parametric and Nonparametric Statistical Procedures:, third edition CRC Press.

Simainga, S., Moreki, J.C., Banda, F., Sakuya, N., 2011. Socio-economic Study of Family Poultry in Mongu and Kalabo Districts of Zambia Livestock Research for Rural Development. 23.

Sonaiya, E.B., 2007. Family poultry, food security and the impact of HPAI.. Worlds Poult. Sci. J. 63, 132-138.

Songolo, A., Katongo, J.C., 2000. 'Country report: Zambia'. In: Alders, R.G., Spradbrow, P.B. (Eds.), Maputo, Mozambique. SADC Planning Workshop on Newcastle Disease Control in Village Chickens: Proceedings of an International Workshop, ACIAR Proceedings 103 43-45. 